\title{
Peripheral nerve function in patients with painful diabetic neuropathy treated with continuous subcutaneous insulin infusion
}

\author{
F W BERTELSMANN,* J J HEIMANS, ${ }^{*}$ J C G M VAN ROOY,* H F DANKMEIJER, $\dagger$ \\ S L VISSER, $\ddagger$ E A VAN DER VEEN $\dagger$
}

\begin{abstract}
From the Departments of Neurology, ${ }^{*}$ Internal Medicine $\dagger$ and Neurophysiology, $\ddagger$ Free University Hospital, Amsterdam, The Netherlands
\end{abstract}

SUMMARY In order to study the effects of improved metabolic control on painful diabetic polyneuropathy, 15 patients were treated with continuous subcutaneous insulin infusion over a 12 month period. Polyneuropathy was assessed by pain score, neurological examinations, nerve conduction studies and determination of sensory thresholds and cardiovascular reflexes. Improved metabolic control was confirmed by significantly improved levels of glycosylated haemoglobin $(11 \cdot 7 \pm 0.3 \%$ at entry to the study, to $8 \cdot 7 \pm 0.3 \%$ after 12 months; mean \pm SEM $)$. Symptomatic relief was confirmed by significantly improved pain scores. Thresholds for thermal cutaneous sensation improved significantly from $6.0 \pm 0.8^{\circ} \mathrm{C}$ at entry to the study to $2.7 \pm 0.7^{\circ} \mathrm{C}$ after 12 months (mean \pm SEM). These findings suggest a selective improvement of peripheral small nerve fibre function after continuous subcutaneous insulin infusion. The importance of quantitating thermal cutaneous sensation in longitudinal studies of patients with diabetic neuropathy was confirmed.

Although the pathogenesis of diabetic neuropathy is still poorly understood, several observations suggest that hyperglycaemia is a major cause of abnormal nerve function and painful neuropathy. ${ }^{1-3}$ This has led to efforts to improve glycaemic control in the management of diabetic patients with neuropathy. 45 It has been shown that the use of an insulin infusion pump is a valuable method for achieving a near normoglycaemia in a diabetic patient. ${ }^{67}$

Several reports have described the effects of continuous subcutaneous insulin infusion therapy on nerve function. ${ }^{8-12}$ However, diabetic patients with painful neuropathy have only been examined in a few trials. $^{13-15}$ Moreover, in these studies, only the function of the largest and fast conducting nerve fibres was monitored.

In the present study we treated a group of 15 diabetic patients suffering from painful polyneuropathy with continuous subcutaneous insulin infusion.

Address for reprint requests: F W Bertelsmann, Department of Neurology, Free University Hospital, De Boelelaan 1117, PO Box 7057, 1007 MB Amsterdam, The Netherlands.

Received 21 October 1986 and in revised form 10 January 1987. Accepted 19 January 1987
Both large and small nerve fibre function was comprehensively assessed every 3 months for a period of 1 year.

\section{Materials and methods}

\section{Subjects}

Fifteen insulin-dependent (type I) diabetic patients, seven females and eight males, were selected for the study. Their ages ranged from 25 to 54 years (mean \pm SEM, $36 \cdot 0 \pm 2 \cdot 3 \mathrm{yr}$ ). Duration of diabetes ranged from seven to 27 years (mean \pm SEM, $15.5 \pm 1.5 \mathrm{yr}$ ). All patients had symptoms and signs of diabetic polyneuropathy. Criteria for diagnosis were sensory complaints (spontaneous pain or paraesthesia) and diminished pin-prick and/or light touch sense in the lower extremities, associated with absent ankle jerks and intact peripheral arterial pulsations. Duration of symptoms ranged from 3 months to 8 years (mean \pm SEM, $2 \cdot 1 \pm 0.5 \mathrm{yr}$ ). Motor signs were not observed in the subjects examined. Five males complained of impotence. Four subjects had diabetic retinopathy. There were no other obvious causes of neuropathy. Haemoglobin, WBC, serum potassium and sodium, renal and hepatic function tests were normal.

\section{Methods}

Continuous subcutaneous insulin infusion therapy The infusion system consisted of a portable battery-driven 
syringe pump. A thin cannula connected the syringe to a needle which was inserted subcutaneously into the anterior abdominal wall. Insulin was administered continuously throughout 24 hours and by boosts just before meal-times. During the initiation period of this out patient study, subjects were taught how to measure their capillary blood glucose, to operate the pump and to insert the needle. Initially, $50-60 \%$ of the previous total daily insulin dose was administered continuously by the pump as the basal rate over a 24 hours period. The rest was infused 15-30 minutes before meals. The subjects measured their blood glucose levels 2-5 times each day and insulin dose was adjusted depending on these levels. The aim of the treatment was to achieve near normoglycaemia $(4-10 \mathrm{mmol} / \mathrm{l})$ at the end of the first 6 months, and to maintain this level for the rest of the study period.

Metabolic studies Overall glycaemic control was monitored by measuring the percentage of glycosylated haemoglobin (HbAl). HbAl was determined according to a microcolumn method (Pierce Instruchemie).

Clinical studies To monitor painful symptoms a horizontal graphic rating scale, running from 1 (no pain) to 20 (severe pain) was used. ${ }^{16}$ Severity of pain was indicated by a number on the scale. Neurological examination included assessment of tendon reflexes, light touch sense (cottonwool) and pain sense (pin-prick). Scores for sensory modalities were related to the anatomic level in leg and arm below which sensation was impaired. $(1=$ toe/finger, $2=$ $\mathrm{mid}-\mathrm{foot} / \mathrm{mid}-\mathrm{hand}, 3=$ ankle $/ \mathrm{wrist}, 4=\mathrm{mid}$ calf $/ \mathrm{mid}$ forearm, $5=$ knee/elbow.

Neurophysiological studies Motor nerve conduction velocity (MNCV), distal latency and F-wave latency (Fd-M interval) of the left peroneal and median nerves were recorded using surface electrodes over the extensor digitorum brevis and abductor pollicis brevis muscles, respectively (Medelec MS 8 electromyograph). MNCV values were corrected to a skin temperature of $33^{\circ} \mathrm{C}$, using the formula: $1^{\circ} \mathrm{C}=2.5 \mathrm{~m} / \mathrm{s}$. The Hoffmann $(\mathrm{H})$ reflex of the soleus muscle was evoked by stimulation of the left tibial nerve in the popliteal fossa. Using surface electrodes maximal $\mathrm{H}$ and $\mathrm{M}$ responses were recorded. The amplitude of the $\mathrm{H}$-response in relation to the amplitude of the $\mathbf{M}$-response (H/M ratio), and the $\mathrm{H}-\mathrm{M}$ interval were measured.

Sensory thresholds were measured for thermal cutaneous sensation and vibratory sensation. The thermal discrimination threshold (TDT) for the dorsum of the left foot was determined using a two-alternative forced-choice method. ${ }^{17}$ Vibratory sensation was measured with a modified biothesiometer. Using the method of limits, the vibratory perception threshold (VPT) was determined for the left first toe. ${ }^{1819}$

Autonomic nerve function was studied by measuring heart rate variability induced by forced breathing and standing. ${ }^{20}$ Heart rate was recorded for one minute during forced breathing with a rate of six breaths/minute. The mean difference of maximum and minimum heart rates was calculated and expressed as inspiration-expiration (I-E) difference. Heart rate (HR) response to standing was expressed as the difference between the maximum HR during the first 15 seconds after standing and the mean HR during 30 seconds before standing ( $\triangle$ HR max). Patients were examined in a quiet room with constant temperature.
Skin temperatures were in the range $29^{\circ}-34^{\circ} \mathrm{C}$.

All investigations were performed at entry of the study and after 3, 6, 9 and 12 months.

Statistical evaluation was performed using analysis of variance with repeated measures. All data are expressed as mean \pm SEM .

\section{Results}

Glycaemic control improved significantly during the study. Figure 1 shows that levels of $\mathrm{HbAl}$ changed from $11.7 \pm 0.3 \%$ at entry to the study to $10 \cdot 3 \pm 0.5 \%$ after 3 months, $9 \cdot 3 \pm 0 \cdot 3 \%$ after 6 months, $9.4 \pm 0.2 \%$ after 9 months and $8.7 \pm 0.3 \%$ after 12 months. $(p<0.0001)$ (non-diabetic range in

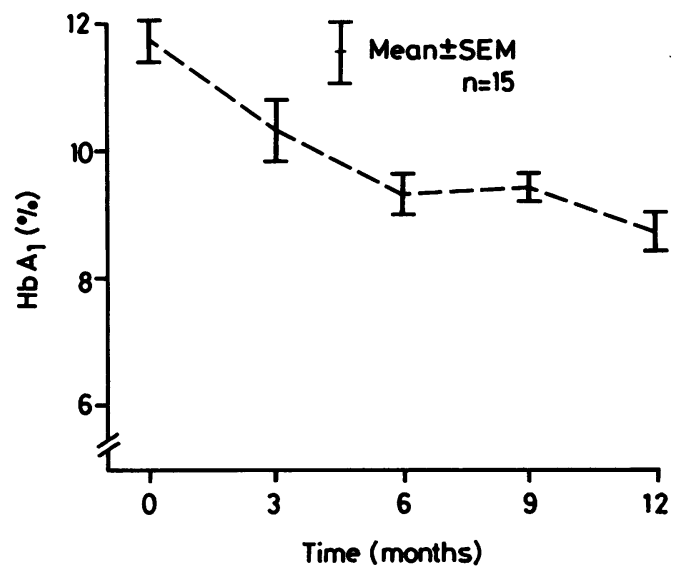

Fig 1 Levels of glycosylated haemoglobin ( $\mathrm{HbAl}$ ) during 12 months' treatment with continuous subcutaneous insulin infusion.

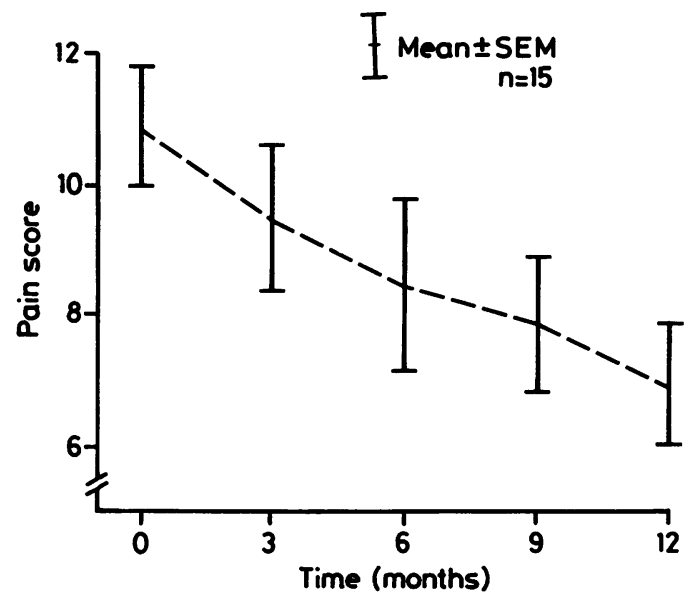

Fig 2 Pain scores during 12 months' treatment with continuous subcutaneous insulin infusion. 
Table Results of neurophysiological measurements during 12 months treatment with continuous subcutaneous insulin infusion

\begin{tabular}{|c|c|c|c|c|c|c|}
\hline & Baseline & $3 \mathrm{mth}$ & $6 m t h$ & $9 m t h$ & $12 \mathrm{mth}$ & Significance \\
\hline $\begin{array}{l}\text { Median MNCV (m/s) } \\
\text { Median distal latency (ms) } \\
\text { Median Fd-M interval (ms) } \\
\text { Peroneal MNCV (m/s) } \\
\text { Peroneal distal latency (ms) } \\
\text { Peroneal Fd-M interval (ms) } \\
\text { H-M interval (ms) } \\
\text { H/M ratio } \\
\text { VPT }(\mu \mathrm{m}) \\
\text { TDT }\left({ }^{\circ} \mathrm{C}\right) \\
\text { I-E difference (beats } / \mathrm{min}) \\
\Delta \text { HR max (beats } / \mathrm{min})\end{array}$ & $\begin{array}{r}48.8 \pm 1.1 \\
3.8 \pm 0.18 \\
28.1 \pm 0.6 \\
39.6 \pm 1.2 \\
5.5 \pm 0.4 \\
54.6 \pm 2.3 \\
32.4 \pm 1.2 \\
0.14 \pm 0.06 \\
57.5 \pm 15.2 \\
6.0 \pm 0.8 \\
10.8 \pm 1.8 \\
19.2 \pm 2.6\end{array}$ & $\begin{array}{r}48.8 \pm 1.3 \\
3.5 \pm 0.07 \\
27.6 \pm 0.4 \\
42.3 \pm 1.1 \\
5.3 \pm 0.3 \\
54.4 \pm 1.8 \\
32.7 \pm 1.0 \\
0.07 \pm 0.02 \\
56.9 \pm 19.9 \\
4.5 \pm 0.8 \\
9.4 \pm 1.5 \\
21.6 \pm 2.2\end{array}$ & $\begin{aligned} 49.0 \pm 1.3 \\
3.8 \pm 0.07 \\
27.7 \pm 0.5 \\
41.0 \pm 1.7 \\
5.8 \pm 0.4 \\
54.6 \pm 2.4 \\
32.5 \pm 1.5 \\
0.12 \pm 0.05 \\
52.4 \pm 17.6 \\
2.6 \pm 0.7 \\
8.8 \pm 1.4 \\
20.0 \pm 2.0\end{aligned}$ & $\begin{array}{l}50.5 \pm 1.6 \\
3.8 \pm 0.13 \\
27.8 \pm 0.5 \\
40.5 \pm 1.2 \\
5.5 \pm 0.3 \\
55.2 \pm 1.9 \\
32.1 \pm 1.2 \\
0.12 \pm 0.06 \\
46.8 \pm 17.3 \\
3.1 \pm 0.8 \\
9.0 \pm 1.3 \\
19.1 \pm 2.0\end{array}$ & $\begin{array}{l}50.0 \pm 1.3 \\
3.7 \pm 0.13 \\
27.7 \pm 0.7 \\
43.4 \pm 1.3 \\
5.5 \pm 0.3 \\
52.7 \pm 1.9 \\
31.5 \pm 0.9 \\
0.06 \pm 0.02 \\
55.0 \pm 16.4 \\
2.7 \pm 0.7 \\
10.4 \pm 1.4 \\
18.8 \pm 1.8\end{array}$ & $\begin{array}{l}\text { NS } \\
\text { NS } \\
\text { NS } \\
\text { NS } \\
\text { NS } \\
\text { NS } \\
\text { NS } \\
\text { NS } \\
\text { NS } \\
\text { p< } 0.001 \\
\text { NS } \\
\text { NS }\end{array}$ \\
\hline
\end{tabular}

Values are expressed in mean \pm SEM

NS in not significant.

p value represents the trend during the complete treatment period.

our laboratory: $3 \cdot 5-5 \cdot 5 \%$ ). There were remarkably few side effects. Although some patients reported needle discomfort, infusion pumps were well tolerated. Two patients had subcutaneous infection at the insertion place of the needle. Severe hypoglycaemic reactions were not observed. Pain scores improved significantly from $10.4 \pm 0.9$ at entry to the study, to $9.0 \pm 1.1$ after 3 months, $8.0 \pm 1.3$ after 6 months, $7.4 \pm 1.0$ after 9 months and $6.5 \pm 0.9$ after 12 months ( $p<0.01$ ) (fig 2). Changes in tendon reflexes were not observed. Sensory level scores did not change significantly $(2 \cdot 6 \pm 0 \cdot 3$ at entry to the study, $2.8 \pm 0.3$ after 3 months, $2.6 \pm 0.3$ after 6 months, $2 \cdot 1 \pm 0.4$ after 9 months and $2 \cdot 1 \pm 0.4$ after 12 months).

Results of neurophysiological studies are shown in the table. The only significant change was a decrease in thermal discrimination thresholds which is in

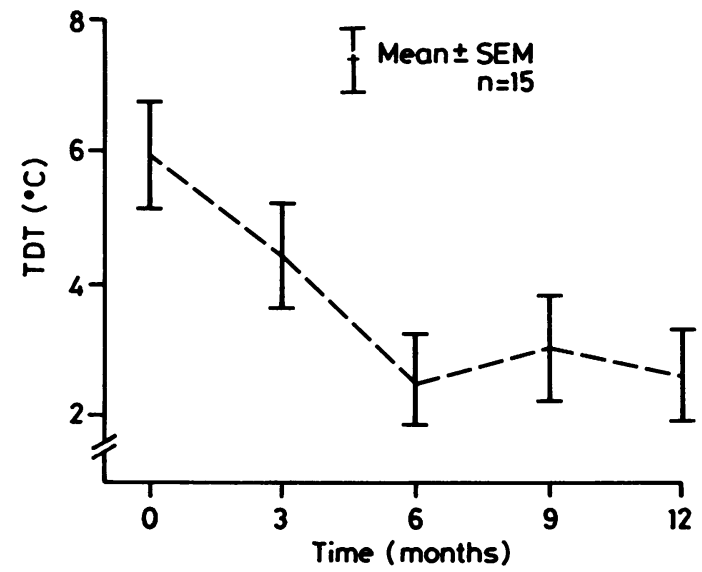

Fig 3 Thermal discrimination thresholds (TDT) during 12 months' treatment with continuous subcutaneous insulin infusion. accordance with improvement in thermal cutaneous sensation (fig 3). (Non-diabetic range in our laboratory: $0 \cdot 1-0 \cdot 5^{\circ} \mathrm{C}$ ). There was a non-significant trend towards improvement in peroneal motor nerve conduction velocity.

\section{Discussion}

The degree of control of hyperglycaemia is considered to be a major factor involved in the genesis of diabetic neuropathy. ${ }^{1-3}$ Although it has been reported that abnormalities of peripheral nerve function may improve after insulin treatment, conventional management of diabetes does not prevent development of polyneuropathy. ${ }^{21}$ This may be related to the difficulty in sustaining normoglycaemia by conventional therapy. ${ }^{22}$ The development of insulin infusion pumps has made it possible to maintain near physiological blood glucose levels for long periods of time. ${ }^{67}$ The newly developed pumps are safe and simple to handle. A major practical advantage of pump treatment for the patient is the flexibility of meal timing because the basal rate of insulin ensures normoglycaemia between meals and because before meals an adequate bolus of short acting insulin can be infused. ${ }^{22}$ It has been reported that continuous subcutaneous insulin infusion treatment may result in improvement in nerve function. ${ }^{8-12}$ Most studies on this subject dealt with patients without symptoms of neuropathy. Only three reports described the effects of continuous subcutaneous insulin infusion on painful neuropathy. ${ }^{13-15}$ These studies were of short duration ranging from 4 weeks to 4 months and the largest group of diabetics examined consisted of only nine patients.

Moreover, quantitation of vibratory sensation and measuremètht of nerve conduction velocities could only determine the function of large myelinated nerve 
fibres. The results of these studies showed relief of painful symptoms and improvements in vibratory perception thresholds, motor nerve conduction velocities and sensory nerve conduction velocities. ${ }^{13-15}$ As we reported previously, the assessment of small nerve fibre function is particularly important in studies of patients with painful diabetic neuropathy. ${ }^{171823}$ Therefore, in the present study, both large and small nerve fibre function were investigated. Nerve conduction studies and measurement of vibratory perception thresholds represented the function of large nerve fibres. Assessment of thermal discrimination thresholds and cardiovascular reflexes represented the function of small nerve fibres. None of the large fibre parameters changed significantly during the study. Evaluation of small fibre parameters shows marked improvement in somatic nerve function. However, no significant change in autonomic nerve function was noted.

Diabetic autonomic neuropathy is usually considered to be an irreversible disorder. ${ }^{24}$ However, slight improvement in cardiovascular tests has been observed after amelioration of metabolic control. ${ }^{25}$ Our data do not confirm this. The significantly decreased thermal discrimination thresholds seen in the present study are consistent with the report of Strian et al. ${ }^{26}$ These authors demonstrated marked improvement of thermal cutaneous sensation during improved glycaemic control in a diabetic patient with painful neuropathy.

Our findings suggest that somatic small nerve fibres are more sensitive to changes in blood glucose levels than autonomic small nerve fibres. Thus, the importance of measuring thermal cutaneous sensation in diabetics with painful neuropathy is confirmed.

Improvement in thermal sensation was accompanied by a significant decrease in painful symptoms. These results are in accordance with our earlier findings that pain in diabetics with neuropathy results from damage to small peripheral nerve fibres. ${ }^{18}$ The overall effect of continuous subcutaneous insulin infusion on peripheral nerve function was, however, not as extensive as we had hoped. The reason for this could be that we studied a group of patients with relatively severe nerve dysfunction. It is possible that in a number of our patients nerve damage was already irreversible. Another reason for the modest changes in the severity of neuropathy may be the degree of hyperglycaemia still present at the end of the study. The aim of the study was to achieve normoglycaemia; this goal was certainly not reached. In highly motivated patients, continuous subcutaneous insulin infusion therapy can result in normoglycaemia. However, our patients were not selected on the basis of motivation for continuous subcutaneous insulin infusion but because of the presence of symptomatic neuropathy.

There may be some controversy concerning the design of this study because of the absence of a control group consisting of patients treated with conventional insulin therapy. However, because of the various characteristics of painful symptoms, it is very difficult to compare patients with painful neuropathy. ${ }^{15}$ For this reason, in the present study, each patient acts as his own control.

As moderate improvement in nerve function and neuropathic symptoms were demonstrated in this study, continuous subcutaneous insulin infusion therapy would seem to be a reasonable option for the treatment of patients with painful diabetic neuropathy.

In order to investigate whether continuous subcutaneous insulin infusion treatment can prevent neuropathy, it is necessary to initiate therapy early in the course of diabetes. In such trials, both large and small peripheral nerve fibre funtion must be assessed.

This study was supported by the Diabetes Research Fund. We are grateful to Mrs WM Felix-Zwerts for her excellent patient education, Miss AHC Busz for technical assistance and Mrs AMM Op't Eijnde-vare Dolen for preparing the manuscript.

\section{References}

1 Pirart J. Diabetes mellitus and its degenerative complications: prospective study of 4400 patients observed between 1947 and 1973. Diabetes Care 1978;1:168-88,252-63.

2 Brown MJ, Asbury AK. Diabetic neuropathy. Ann Neuro 1984;15:2-12.

3 Greene DA, Lattimer S, Ulbrecht J, Carroll P. Glucose-induced alteration in nerve metabolism: current perspective on the pathogenesis of diabetic neuropathy and future directions for research and therapy. Diabetes Care 1985;8:290-9.

4 Holman RR, Mayon-White V, Orde-Peckar C, et al. Prevention of deterioration of renal and sensory-nerve function by more intensive management of insulin-dependent diabetic patients. Lancet 1983;1:204-8.

5 Service FJ, Daube JR, G'Brien PC, et al. Effect of blood glucose control on peripheral nerve function in diabetic patients. Mayo Clin Proc 1983;58:283-9.

6 Pickup JC, Keen H, Viberti GC, et al. Continuous subcutaneous insulin infusion in the treatment of diabetes mellitus. Diabetes Care 1980;3:290-300.

7 Sherwin RS, Tamborlane WV, Genel M, Felig P. Treatment of juvenile-onset diabetes by subcutaneous infusion of insulin with a portable pump. Diabetes Care 1980;3:301-8.

8 Troni W, Carta Q, Cantello R, Caselle MT, Rainero J. Peripheral nerve function and metabolic control in diabetes mellitus. Ann Neurol 1984;16:178-83.

9 Reeves ML, Seigler DE, Ayyar DR, Skyler JS. Medial plantar sensory response. Sensitive indicator of peripheral nerve dysfunction in patients with diabetes mellitus. $A m J \mathrm{Med}$ 1984;76:842-6.

10 Service FJ, Rizza RA, Daube JR, O'Brien PC, Dyck PJ. Near normoglycaemia improved nerve conduction and vibration sensation in diabetic neuropathy. Diabetologia 1985;28:722-7. 
11 Ehle AL, Raskin P. Increased nerve conduction in diabetes after a year of improved glucoregulation. J Neurol Sci 1986;74: $191-7$.

12 Dahl-Jorgensen K, Brinchmann-Hansen O, Hanssen KF, et al. Effect of near normoglycaemia for two years on progression of early diabetic retinopathy, nephropathy and neuropathy: the Oslo study. Br Med J 1986;293:1195-99.

13 Pietri A, Ehle AL, Raskin P. Changes in nerve conduction velocity after six weeks of glucoregulation with portable insulin infusion pumps. Diabetes 1980;29:668-71.

14 Tolaymat A, Roque JL, Russo LS. Improvement of diabetic peripheral neuropathy with the portable insulin infusion pump. South Med J 1982;75:185-9.

15 Boulton AJM, Drury J, Clarke B, Ward JD. Continuous subcutaneous insulin infusion in the management of painful diabetic neuropathy. Diabetes Care 1982;5:386-90.

16 Scott J, Huskisson EC. Graphic representation of pain. Pain 1976;2:175-84.

17 Bertelsmann FW, Heimans JJ, Weber EJM, Van der Veen EA, Schouten JA. Thermal discrimination thresholds in normal subjects and in patients with diabetic neuropathy. $J$ Neurol Neurosurg Psychiatry 1985;48:686-90.

18 Heimans JJ, Bertelsmann FW, Van Rooy JCGM. Large and small nerve fiber function in painful diabetic neuropathy. J Neurol Sci 1986;74:1-9.

19 Bertelsmann FW, Heimans JJ, Van Rooy JCGM, Heine RJ, Van der Veen EA. Reproducibility of vibratory perception thresh- olds in patients with diabetic neuropathy. Diabetes Research 1986;3:463-6.

20 Wieling W, Van Brederode JFM, de Rijk LG, Borst C, Dunning AJ. Reflex control of heart rate in normal subjects in relation to age: a data base for cardiac vagal neuropathy. Diabetologia 1982;22:163-6.

21 Dyck PJ, Brown M, Greene D, et al. Does improved control of glycaemia prevent or ameliorate diabetic polyneuropathy. Ann Neurol 1986;19:288-90.

22 Schiffrin A, Belmonte MM. Comparison between continuous subcutaneous insulin infusion and multiple injections of insulin. A one-year prospective study. Diabetes 1982;31:255-64.

23 Bertelsmann FW, Heimans JJ, Van Rooy JCGM, Visser SL. Comparison of Hoffman reflex with quantitative assessment of cutaneous sensation in diabetic neuropathy. Acta Neurol Scand 1986;74:121-7.

24 Ewing DJ, Campell IW, Clarke BF. The Natural history of diabetic autonomic neuropathy. Q J Med 1980;193:95-108.

25 Fedele B, Bellavere F, Cardone C, Ferri M, Crepaldi G. Improvement of cardiovascular autonomic reflexes after amelioration of metabolic control in insulin-dependent diabetic subjects with severe autonomic neuropathy. Horm Metab Res 1985;17:410-3.

26 Strian F, Severin F, Muller J, Montag N. Diagnose der diabetischen "painful small fibre neuropathy" mit hilfe der Temperaturempfindlichkeitsschwellen. Nervenarzt 1984;55: 103-7. 